\title{
Modelling the hydraulic link between the Prespa and Ohrid Lakes
}

\author{
E. Anovska-Jovcheva ${ }^{1}$, V. Popov ${ }^{2} \&$ T. Anovski ${ }^{1}$ \\ ${ }^{1}$ Faculty of Technology and Metallurgy, \\ University of Sts Cyril and Methodius, Republic of Macedonia \\ ${ }^{2}$ Wessex Institute of Technology, Environmental and Fluid Mechanics, \\ Southampton, UK
}

\begin{abstract}
The Prespa-Ohrid lake system is shared between Greece, Republic of Macedonia (Former Yugoslav Republic) and Albania. In the recent years a water decrease in the Prespa Lake has triggered a number of studies on this very complex and important water system. As part of an international research project in which institutions from the UK, Greece, R. Macedonia and Albania took part, which was supported by the NATO Science for Peace (SfP) programme, the problem of water loss in the Prespa Lake has been investigated. Previous studies have established that the water from the Prespa Lake flows into the Ohrid Lake through the Galichica Mountain. As part of the study the flow through the mountain has been analysed using a free surface flow model. The model has been solved using a multi-domain boundary element method approach.

Keywords: Prespa-Ohrid lake system, free surface groundwater flow, Galichica aquifer.
\end{abstract}

\section{Introduction}

Three lakes: Ohrid, Big Prespa and Small Prespa are on the borders between Albania, Republic of Macedonia and Greece, see Figure 1. A hypothesis published at the beginning of the $20^{\text {th }}$ century [1] predicted that the water from the Prespa Lake drains into Ohrid Lake through the Galichica and Dry mountains, which separate the two lakes. Investigations involving the use of natural isotopes $\left(\delta^{18} \mathrm{O},{ }^{2} \mathrm{H},{ }^{3} \mathrm{H}\right)$ [2] confirmed the validity of the hypothesis. Figure 2 presents a simplified cross section of the karstic massif of Galichica and Mali and Thate with connection between Big Prespa and Ohrid Lakes. 


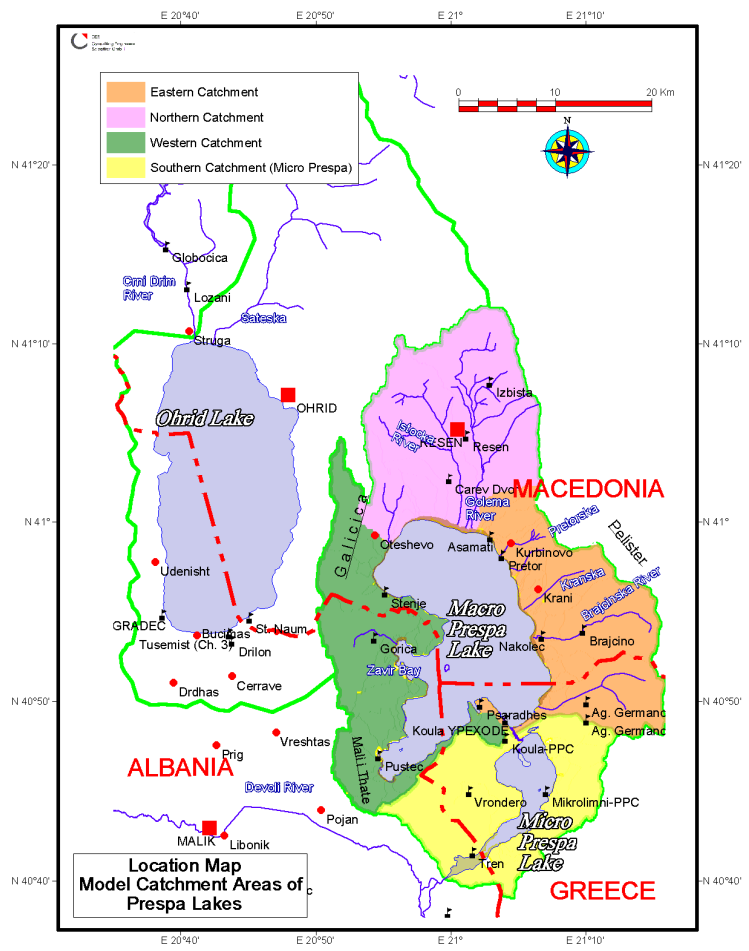

Figure 1: Ohrid, big Prespa and small Prespa Lakes with catchments for rainfall-runoff [10].

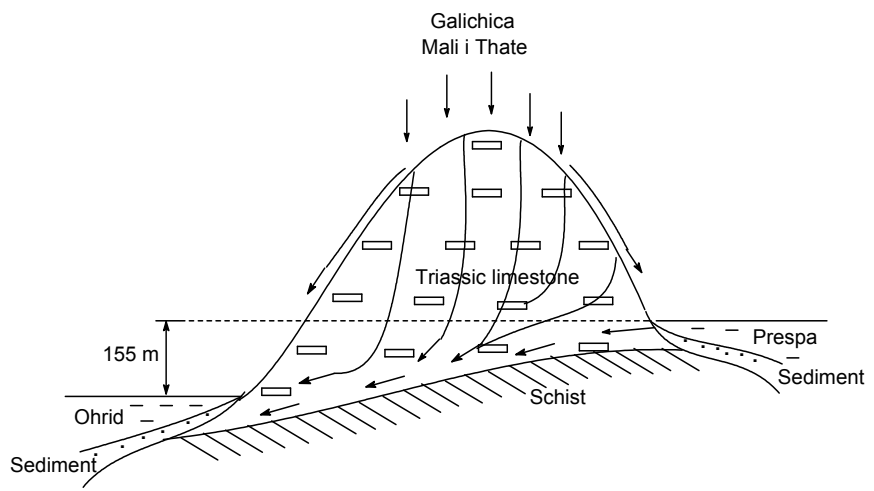

Figure 2: $\quad$ Simplified cross section of karstic massif of Galichica and Mali and Thate with connection between big Prespa Lake and Ohrid Lake.

The Ohrid Lake $\left(348 \mathrm{~km}^{2}\right)$ at an elevation of $695 \mathrm{~m}$ a.s.l. is registered by UNESCO as World's heritage. 
The Lakes Big Prespa $\left(253.6 \mathrm{~km}^{2}\right)$ and Small Prespa $\left(47.4 \mathrm{~km}^{2}\right)$ are at $847 \mathrm{~m}$ a.s.1. and $850 \mathrm{~m}$ a.s.l., respectively, and are linked by a small channel with a sluice that separates the two lakes. In the past, periodical oscillations of the lake's level were in the range of one to three metres, depending on the amount of rain in the season. After the mid 80's, a steady decrease of the water level has been recorded that disturbs the ecological balance of the lake and the watershed area resulting in serious consequences for the fishing and tourist industry in the trans-boundary Prespa region. In addition to this, the industrial activities as well as the overuse of the herbicides in agriculture activities raised the problem of pollution of the water in the Prespa Lake.

The importance of Prespa Lake has been recognised worldwide because of its high biodiversity, including populations of rare water birds, like for example the Dalmatian pelican.

State authorities of the three countries have enforced the protection status of Prespa through the use of national and international legislative means. A large part of the lakes and catchment basin has been characterized as a National Park (Albania and Greece) or/and a Wetland of International Importance under the Ramsar Convention (Greece, R. Macedonia).

\section{Model description}

The equation for the steady - state saturated flow through an anisotropic porous medium can be written as:

$$
\frac{\partial}{\partial x}\left(K_{x} \frac{\partial \Phi}{\partial x}\right)+\frac{\partial}{\partial y}\left(K_{y} \frac{\partial \Phi}{\partial y}\right)+\frac{\partial}{\partial z}\left(K_{z} \frac{\partial \Phi}{\partial z}\right)=0
$$

When isotropic homogenous medium is taken into account, $\mathrm{K}=$ constant, (1) becomes:

$$
\frac{\partial^{2} \Phi}{\partial x^{2}}+\frac{\partial^{2} \Phi}{\partial y^{2}}+\frac{\partial^{2} \Phi}{\partial z^{2}}=0
$$

which represents the Laplace equation, where $\Phi(\mathrm{x}, \mathrm{y}, \mathrm{z})$ is the hydraulic head.

\subsection{Free surface flow}

In porous media flow when unconfined aquifer is considered, as in the present case, free surface flow is formed, as the upper boundary of the aquifer is the water table. Figure 3 illustrates the free surface flow through an earth dam for unconfined saturated ground water flow. The theory is presented in more details in Refs. $[3,4]$. The following boundary conditions (BCs) were applied. The free surface elevation, line $b$ in Figure 3, is given by:

$$
z=\eta(x, y, t)
$$

As illustrated in Figure 3, $a$ and $d$ are the upstream and downstream surfaces, respectively, $b$ is the free surface, $c$ is the seepage surface, and $e$ is the 
impervious bottom. On the upstream surface $a$ and downstream surface $d$ the potentials are given as:

$$
\Phi_{a}=h_{1} \text { and } \Phi_{d}=h_{2}
$$

On the seepage surface $c$ the potential is given as:

$$
\Phi_{c}=z
$$

The normal derivative along the impervious bottom $e$ is

$$
\frac{\partial \Phi_{e}}{\partial n}=0
$$

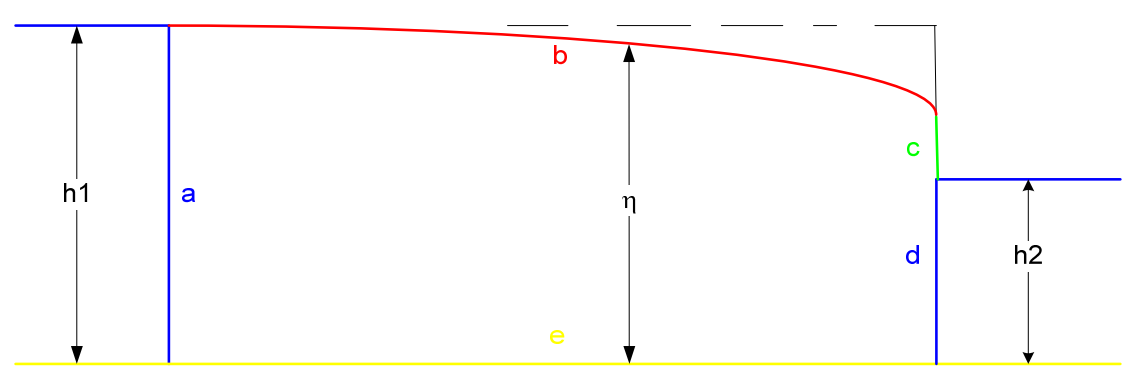

Figure 3: $\quad$ Free surface flow through an earth dam.

Along the free surface $b$ the potential for the two-dimensional flow and the relation between the potential and the free surface elevation, see [3, 4], can be written as

$$
\Phi=\eta(x, t) \text { on } z=\eta
$$

The following non-linear boundary condition (BC) on the free surface completes the formulation:

$$
\frac{\partial \Phi}{\partial t}=-K \frac{1}{\cos \beta} \frac{\partial \Phi}{\partial n}
$$

where $n$ is the unit normal to the free surface. This BC can be represented in a finite difference form as:

$$
\Phi_{I}^{k+1}=\Phi^{k}-K \frac{\Delta t}{\cos \beta_{I-1}^{k+1}}\left[\theta\left(\frac{\partial \Phi}{\partial n}\right)_{I}^{k+1}+(1-\theta)\left(\frac{\partial \Phi}{\partial n}\right)^{k}\right]
$$

In the above equation $k$ represents the time step and $I$ represent the iteration used within each time step until convergence of the solution is obtained. The iterative procedure helps to update the angle $\beta$ between the free surface and $\mathrm{x}$ coordinate, within time level $k+1$, as its value is initially taken from time level $k$, although the equation is written for the time level $k+1$. 


\section{Boundary element method}

By combining the free space Green's function, also known as the fundamental solution, with equation (2), and by applying the divergence theorem, the following equation can be obtained [5]:

$$
c(\xi) \Phi(\xi)+\int_{\Gamma} \Phi(x) \frac{\partial \Phi^{*}(\xi, x)}{\partial n} d \Gamma=\int_{\Gamma} \frac{\partial \Phi(x)}{\partial n} \Phi^{*}(\xi, x) d \Gamma
$$

where: $\mathrm{c}(\xi)$ is a constant related to the internal angle of the boundary $\Gamma$ at point $\xi$; $\Phi(x)$ is potential at field point $x ; \Phi^{*}(\xi, x)$ is the fundamental solution of the Laplace equation; $\partial \Phi(\xi, x) / \partial n$ is the normal derivative of the fundamental solution. More information on the boundary element method (BEM) can be found in [5].

The discretized form of (10) can be written as

$$
\frac{1}{2} \Phi_{i}+\sum_{j=1}^{N}\left(\int_{\Gamma_{i}} \frac{\partial \Phi^{*}}{\partial n} d \Gamma\right) \Phi_{j}=\sum_{j=1}^{N}\left(\int_{\Gamma_{i}} \Phi^{*} d \Gamma\right) \frac{\partial \Phi_{j}}{\partial n}
$$

where $\mathrm{N}$ elements have been used to represent the boundary $\Gamma$. More details on the implemented algorithm can be found in [6].

\subsection{BEM with sub-domains}

When studying groundwater flow the domain under consideration can be divided into several homogenous sub-domains with different characteristics. Applying the BEM on each sub domain and using specific rules when treating the interface boundaries, a set of equations is created that describes the flow in the domain. By solving these equations the unknown values of $\Phi$ and $\partial \Phi / \partial n$ are found. Figure 4 illustrates the domain $\Omega$ with two homogenous sub-domains $\Omega_{1}$ and $\Omega_{2}$ that have different constant conductivities $K_{1}$ and $K_{2}$ respectively. More information on the BEM implementation with sub-domains can be found in [7] and [8].

The BEM sub-domain approach was implemented in the computer program GMFlow, which is an object-oriented computer program developed using the C\# programming language. More on the implementation can be found in [6].
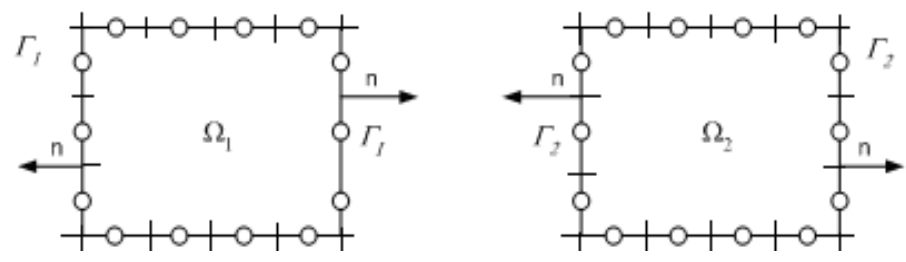

Figure 4: $\quad$ Domain $\Omega$ with two homogenous sub-domains $\Omega 1$ and $\Omega 2$. 


\section{Numerical results}

\subsection{Flow through a dam}

In order to test the accuracy of the developed GMFlow program [6], the same example presented by Liggett and Liu for an earth dam [9] has been used. Figure 5 shows the region of interest and illustrates the BCs that are applied. Figure 6 shows the results for change of hydraulic head on the free surface compared to the results reported by Liggett and Liu. Figure 7 shows the final mesh representing the domain after steady state solution is achieved. The nine subdomains were squares at the beginning of the simulation and it can be seen that all the sub-domains have been deformed during the solution process. This is done in order not to have extreme deformation at the top sub-domains.

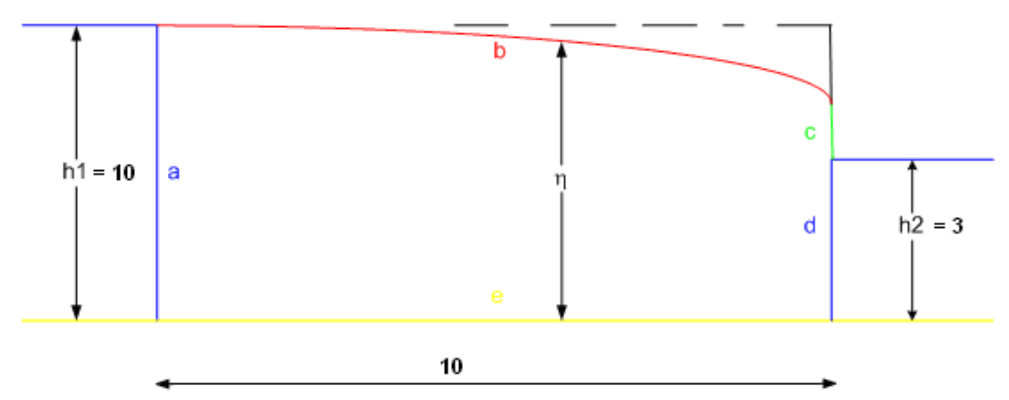

Figure 5: Geometry of the example with earth dam.

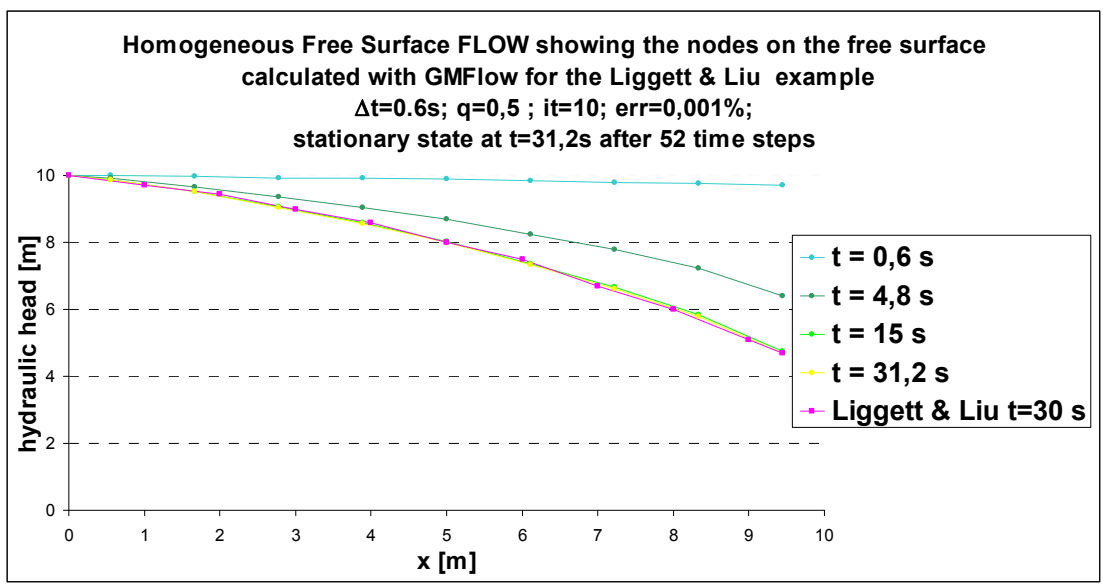

Figure 6: Hydraulic head for the nodes on the free surface compared to the results of Liggett and Liu at steady state. 


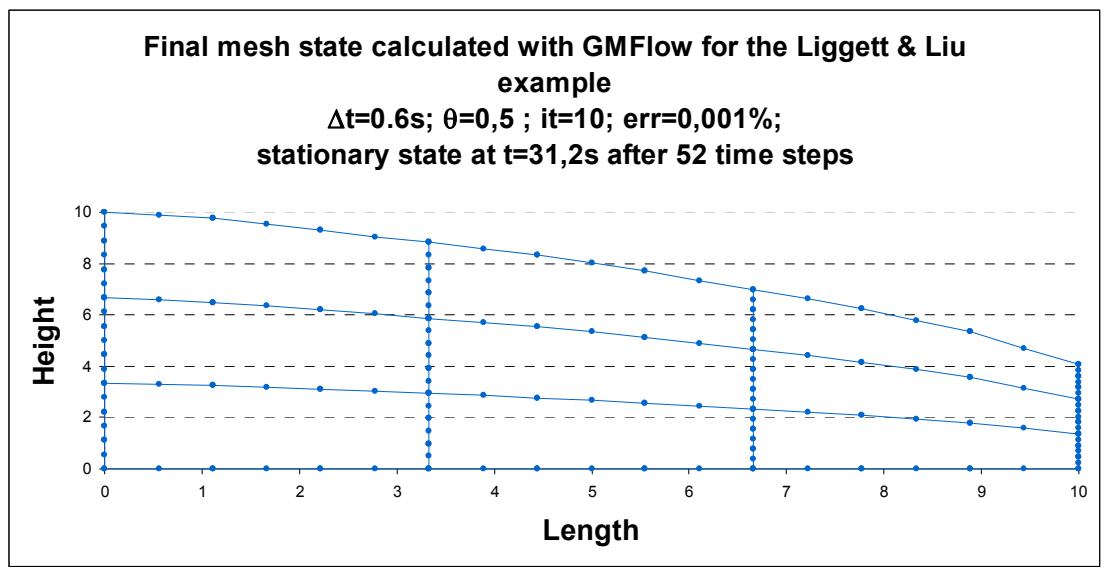

Figure 7: $\quad$ Final mesh of the domain after reaching steady state.

\subsection{Flow through Galichica Mountain}

The free surface flow through Galichica Mountain was performed as if the domain of interest was homogenous with constant hydraulic conductivity $\mathrm{K}=$ $2.6 \times 10^{-4} \mathrm{~m} / \mathrm{s}$. This value was determined based on several drillings in the area of interest, which were carried out by the Institute for Geological and Mineral Exploration, Athens, Greece. The second example considers the Galichica aquifer as non-homogenous where the values for $\mathrm{K}$ ranged from $4.6 \times 10^{-4} \mathrm{~m} / \mathrm{s}$ to $0.4 \times 10^{-4} \mathrm{~m} / \mathrm{s}$. Galichica Mountain as a multi domain region with 66 sub-domains and corresponding $\mathrm{BC}$ is shown in Figure 8.

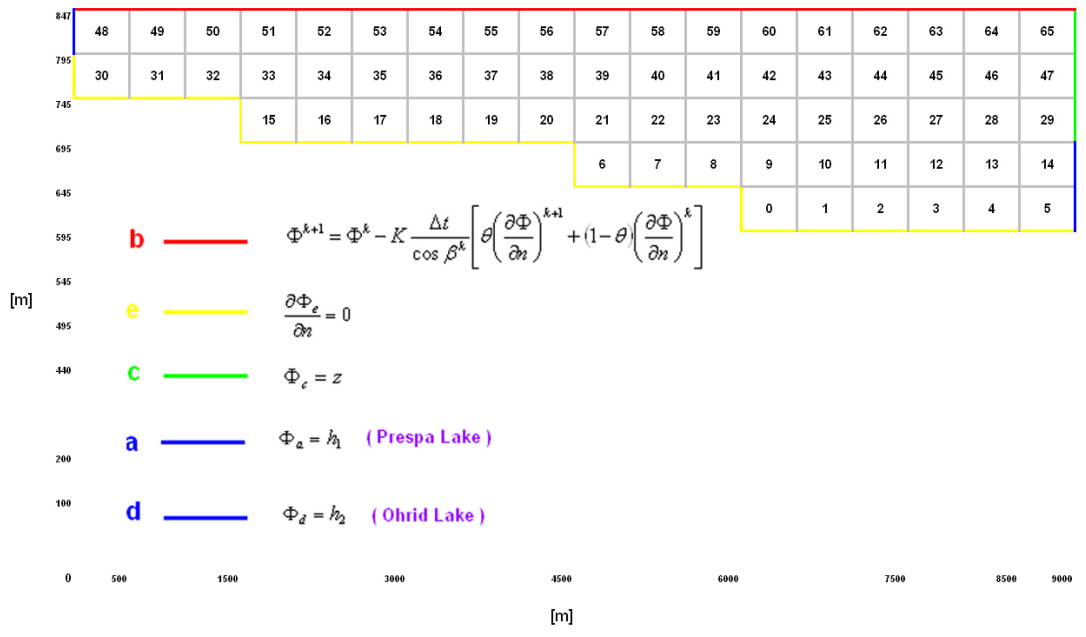

Figure 8: Galichica mountain represented using 66 sub-domains and corresponding BC (distance between lakes $=9 \mathrm{~km})$. 


\subsubsection{Case of homogeneous aquifer}

Galichica Mountain is considered as a homogenous region modeled in this case using 66 sub-domains with hydraulic conductivity $\mathrm{K}=2.6 \times 10^{-4} \mathrm{~m} / \mathrm{s}$ [6].

Figure 9 shows the hydraulic head obtained on the free surface using the GMFlow program. Figure 10 illustrates the final mesh generated by the GMFlow program after reaching steady state.

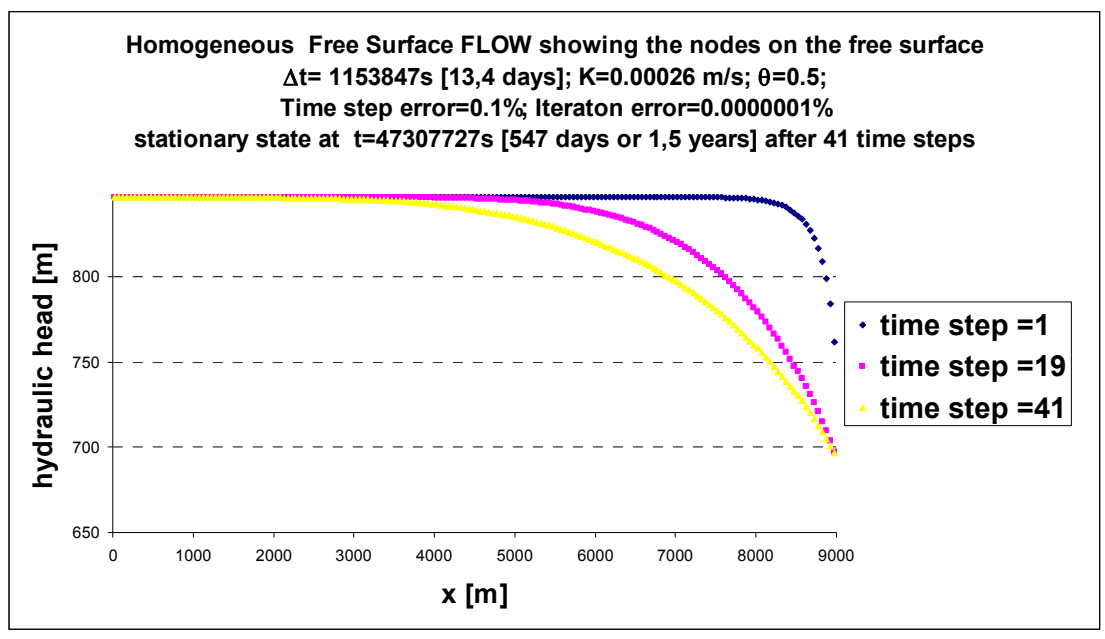

Figure 9: Hydraulic head for the nodes on the free surface.

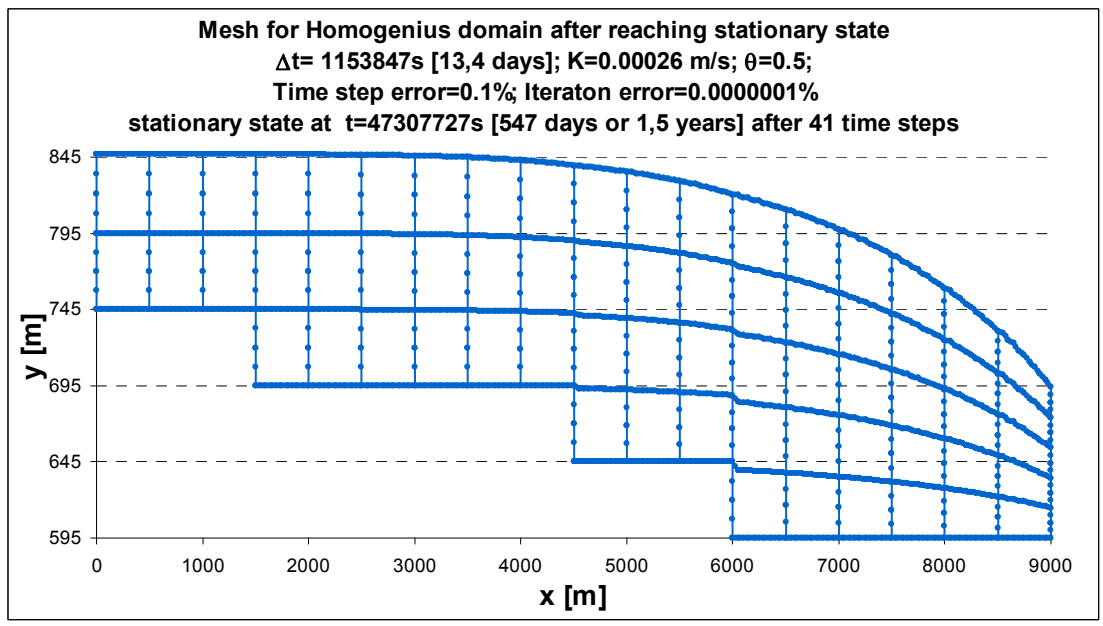

Figure 10: Mesh of the domain after reaching steady state. 


\subsubsection{Case of non-homogeneous aquifer}

In this case the Galichica Mountain is considered as a non-homogenous multi domain region with 66 sub-domains and for each region different hydraulic conductivity is given [6].

Figure 11 shows the hydraulic head on the free surface obtained using the GMFlow program. Figure 12 illustrates the final mesh generated by the GMFlow program after reaching the steady state.

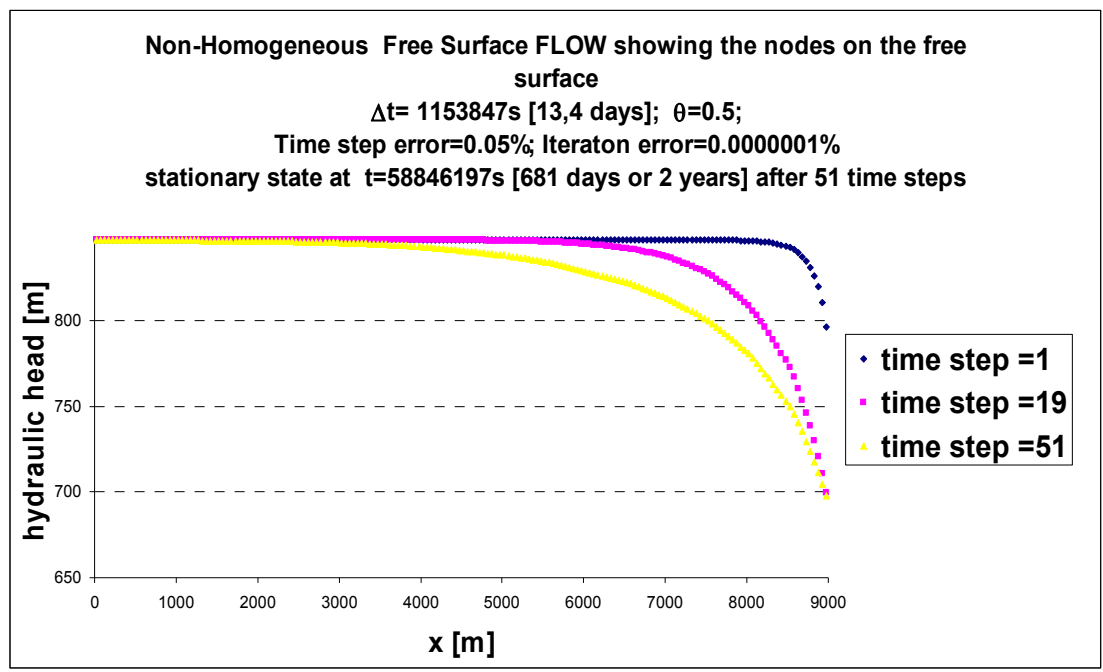

Figure 11: Hydraulic head for the nodes on the free surface.

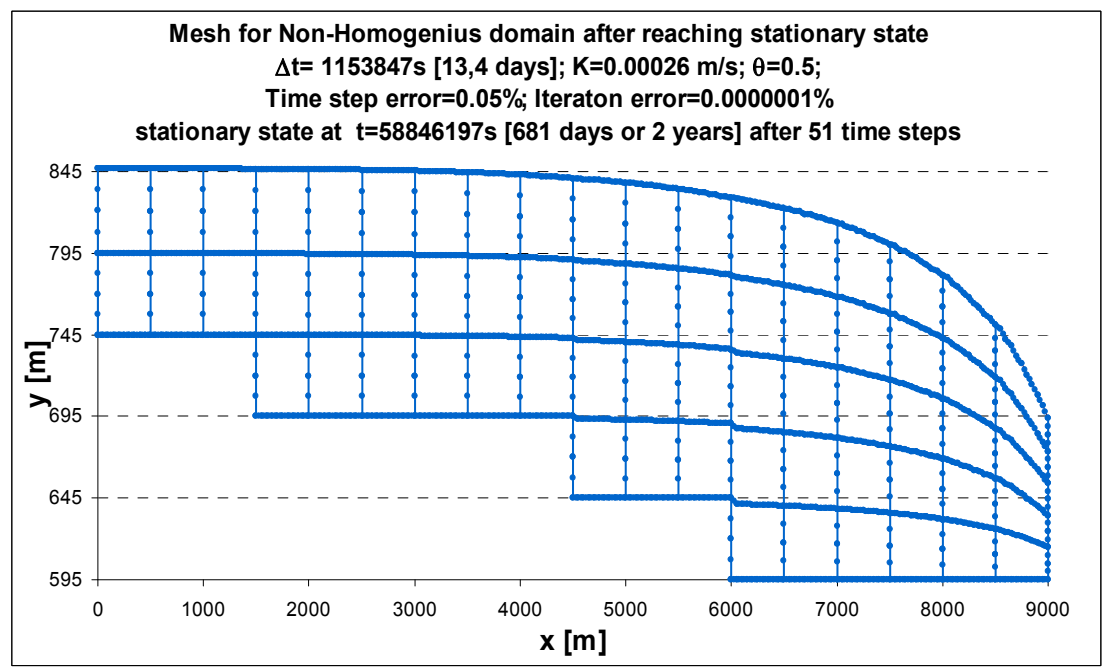

Figure 12: Mesh of the domain after reaching steady state. 


\section{Calculating equivalent hydraulic conductivity $K$}

Using the results from the GMFlow program the equivalent hydraulic conductivity $\mathrm{K}$ for the non-homogeneous example according to (12) can be calculated using

$$
Q=K \times L \times \sum_{i} q_{i} \times h_{i}
$$

where: Q is the total flow through Galichica Mountain from Prespa Lake to Ohrid Lake $\left[\mathrm{m}^{3} / \mathrm{s}\right] ; \mathrm{K}$ is the hydraulic conductivity $[\mathrm{m} / \mathrm{s}] ; \mathrm{L}$ is length of the coastal line of Ohrid Lake where springs appear $[\mathrm{m}] ; q_{\mathrm{i}}$ is the equivalent normal derivative of the hydraulic head at nodes on the right side of the domain; $h_{i}$ is the equivalent height were the nodes on the right side of the domain are positioned (difference in height between the highest and the lowest node) [m].

Taking into account $\mathrm{Q}=8.7 \mathrm{~m}^{3} / \mathrm{s}$ as estimated from previous studies [6], the equivalent normal derivative of the nodes, the equivalent height and by applying Eq. (12) the following properties of the aquifer can be estimated:

- When homogeneous domain is considered, by using $\mathrm{Ke}=2.6^{*} 10^{-4} \mathrm{~m} / \mathrm{s}$, equivalent height $h_{i}=89,23 \mathrm{~m}$ and equivalent normal derivative of the nodes $q_{i}=0.1$, one can calculate the length of the coast line of Ohrid Lake where springs appear as $\mathrm{L}=3750 \mathrm{~m}$, which is in agreement with the observations.

- Considering L from the example of homogeneous aquifer, when nonhomogeneous domain is considered the equivalent hydraulic conductivity according to (12) can be calculated as $\mathrm{Ke}=1.54 \times 10^{-4} \mathrm{~m} / \mathrm{s}$, considering the equivalent height $h_{i}=89.13 \mathrm{~m}$ and equivalent normal derivative of the nodes $q_{i}=0.169$. The hydraulic conductivity is not the same as when the aquifer was considered as homogeneous. However, the intention was to determine the order of magnitude of the aquifer characteristics rather than exact values. The normal derivative of the hydraulic head is somewhat higher for the non-homogeneous aquifer since the hydraulic conductivity of the aquifer is considered to be lower closer to Ohrid Lake.

\section{Conclusions}

It can be concluded that:

1. The BEM with domain decomposition is convenient for modeling of freesurface groundwater flow, for both, homogeneous as well as nonhomogeneous aquifers.

2. The GMFlow can be used to calculate the equivalent hydraulic conductivity for a given region, an earth dam, free surface aquifer or other.

3. The GMFlow software is user friendly offering graphical user interface through which one can easily adjust the time step, geometry and boundary conditions, weighting factor, precision, number of time steps and iterations, and number of elements in each region. 
4. The model was verified towards the results previously published by Liggett and Liu showing very good agreement.

5. The program has its own limitations which are mentioned below, however, removing this limitations is straightforward and this work is left for the future:

- $\quad$ equal number of elements per region are created

- the mesh is constructed of sub-domains with equal size and shape

6. The model helped understand the equivalent properties of the nonhomogeneous Galichica aquifer as well as the hydraulic link between the two lakes.

\section{Acknowledgement}

This work was supported by the NATO Science for Peace and Security programme (Project No. SfP 981116).

\section{References}

[1] Cvijic, J. (1906) Fundamentals of Geography and Geology of Macedonia and Serbia, Special Edition VIII, Belgrade.

[2] Anovski, T. et al. (1980), "A study of the origin of water in the St. Naum's Springs, Lake Ohrid", FIZIKA - A Journal of Experimental and Theoretical Physics, Vol. 12 (S2).

[3] Freeze, R.A., Cherry, A. J. 'Groundwater', Prentice-Hall, Inc., Englewood Cliffs, New Jersey, 1979, pp. 15-76.

[4] Lennon, G.P., Liu, P.L.-F. and Liggett, J.A., 1980, Boundary integral solutions to three-dimensional unconfined Darcys flow. Water Resources Research, 16, 651-658.

[5] Brebbia, CA., Telles, J.C.F., Wrobel, LC., 'Boundary Element Techniques', Berlin: Springer-Verlag, 1984.

[6] Anovska-Jovcheva E. (2010) Application of the Boundary Element Method Multi-Domain Approach and simulation of tritium concentration for determining the properties of the Galichica Mountain aquifer. MPhil thesis, University of Wales (research carried out at the Wessex Institute of Technology).

[7] Tu, B.T., V. Popov (2009). A domain decomposition Boundary Element Method with overlapping sub-domains. Engineering Analysis with Boundary Elements. 33, 456-466.

[8] Natalini, B, Popov, V. (2007) On the optimal implementation of the dual reciprocity method - multi domain approach for 3D problems', Engineering Analysis with Boundary Elements, 31, 275-287.

[9] Liggett, J.A., Liu, P.L-F., 'The Boundary Integral Method for Porous Media Flow', Gorge Allen \& Unwin (Publishers) Ltd, London, UK, 1983, pp.1-87.

[10] KfW Feasibility Study, Transboundary Prespa Park Project, 2006. 